\title{
ANALISIS PENGENDALIAN KUALITAS PADA PRODUKSI LAMPU TL DI PT PHILIPS INDONESIA DENGAN PETA KENDALI $U$ DAN DECISION ON BELIEF (DOB)
}

\author{
VIKI ANDRIANI, FERRA YANUAR*'YUDIANTRI ASDI \\ Program Studi S1 Matematika, \\ Fakultas Matematika dan Ilmu Pengetahuan Alam, Universitas Andalas, \\ Kampus UNAND Limau Manis Padang, Indonesia. \\ email : vikiandriani20@gmail.com,ferrayanuar@yahoo.co.id,yudiantriasdi@gmail.com
}

Diterima 31 Januari $2021 \quad$ Direvisi 9 Maret $2021 \quad$ Dipublikasikan 29 April 2021

\begin{abstract}
Abstrak. Pengendalian kualitas statistik merupakan salah satu usaha yang dilakukan untuk mengurangi jumlah produk yang cacat. Salah satu metode pengendalian kualitas statistik yang digunakan adalah peta kendali. Peta kendali terdiri dari dua macam yaitu peta kendali atribut dan peta kendali variabel. Peta kendali $U$ merupakan peta kendali atribut yang digunakan untuk ukuran sampel yang sama dan juga ukuran sampel yang berbeda. Salah satu konsep metode baru pengendalian kualitas statistik dari peta kendali univariat atribut adalah peta kendali Decision On Belief (DOB). Pada penelitian ini membandingkan hasil kinerja dari peta kendali $U$ dan peta kendali(DOB). Hasil analisis dan pembahasan diperoleh bahwa kinerja dari peta kendali DOB lebih baik daripada peta kendali $U$, karena mampu mendeteksi jumlah data out of control lebih banyak sebesar 17,86\% dibandingkan dengan menggunakan peta kendali $U$.
\end{abstract}

Kata Kunci: Pengendalian Kualitas Statistik, Peta Kendali DOB, Peta Kendali $U$

\section{Pendahuluan}

PT Philips Indonesia merupakan salah satu perusahaan terbesar sebagai produsen lampu ternama di dunia dengan produksi mencapai ratusan juta lampu per tahun. Perusahaan yang bertempat di Jalan Berbek Industri I 5-19 Sidoarjo ini memiliki proses produksi 5 VTL dan hanya 2 VTL yang digunakan setiap kali produksi. Untuk setiap VTL memiliki 7 subproses produksi, dimana subproses tersebut terdiri dari beberapa kriteria lampu reject [5].

Perhatian utama yang di lakukan disini adalah memperhatikan kualitas produksi untuk menghasilkan produk yang baik, dapat memberi kepuasan untuk para konsumen dan juga memberikan untung bagi perusahaan dengan membantu

*penulis korespondensi 
mengurangi kegagalan dalam produksi. Salah satu metode kualitas yang erat kaitannya dengan hal tersebut adalah Pengendalian Kualitas Statistik atau Pengendalian Proses Statistik [1].

Pengendalian kualitas statistik (statistical quality control) adalah bagan visual untuk memberi gambaran proses yang sedang berjalan untuk mengetahui apakah proses berada di dalam batas-batas yang telah ditetapkan sebelumnya atau tidak. Pada ilmu tentang kualitas, kualitas produk dapat diukur dengan menggunakan batas spesifikasi, oleh karena itu, perlu adanya suatu pengendalian agar tercapainya sebuah standar kualitas sehingga untuk mendapatkan standar kualitas yang dapat digunakan untuk pengendalian kualitas disebut peta kendali.

Peta kendali terdiri dari dua macam, yaitu peta kendali variabel dan peta kendali atribut. Peta kendali variabel bertujuan untuk mengendalikan suatu proses produksi dengan karakteristik kualitas produk yang dinyatakan dalam skala numerik. Peta kendali atribut bertujuan untuk mengendalikan proses produksi dengan karakteristik kualitas produk yang diukur dengan skala kategorik [1].

Salah satu metode lama dalam peta kendali adalah peta kendali $U$. Peta kendali $U$ merupakan peta kendali atribut yang digunakan untuk melihat proses suatu produksi sudah terkendali secara statistik atau belum dengan melihat titik-titik yang keluar dari batas kendali yang telah ditentukan dengan rumus yang sudah ada sebelumnya. Peta kendali $U$ dapat digunakan untuk jumlah sampel yang konstan dan tidak konstan.

Sebuah konsep metode baru yang diperkenalkan oleh [4] adalah peta kendali Decision On Belief (DOB) yang merupakan peta kendali yang didasarkan pada Teorema Bayes. Peta kendali DOB digunakan untuk menganalisis dan mengklasifikasikan keadaan sistem pengendalian kualitas dengan menggunakan data univariat atribut.

\section{Landasan Teori}

\subsection{Pengendalian Kualitas Statistika}

\subsubsection{Kualitas}

Kualitas atau mutu adalah karakteristik suatu produk (barang/jasa) yang menunjang kemampuannya untuk memenuhi kebutuhan atau harapan pelanggan yang telah ditetapkan sesuai dengan kebutuhan atau harapan pelanggan [6]. Dalam proses suatu produk oleh perusahaan terkadang tidak selalu berhasil dengan hasil yang baik, karena ketidak sesuai dapat terjadi didalam proses memproduksi seperti terjadinya kesalahan yang tidak diduga dalam memproduksi produk tersebut. Oleh karenanya diperlukan pengendalian agar dapat diketahui apa saja penyebab terjadinya kesalahan yang terjadi tersebut dengan standar kualitas.

\subsubsection{Pengendalian Kualitas}

Pengendalian kualitas merupakan sebuah kegiatan yang dimulai dari pengendalian standar kualitas pada bahan, proses pengolahan bahan, barang setengah jadi, hingga tahap akhir yaitu pengiriman kepada konsumen dengan harapan akan sesuai 
dengan spesifikasi kualitas yang telah direncanakan sebelumnya.

\subsubsection{Pengendalian Kualitas Statistik}

Pengendalian kualitas statistik adalah salah satu teknik yang digunakan untuk mengendalikan, memonitor, mengelola, menganalisa, dan memperbaiki suatu proses dengan menggunakan metode statistik. Sasaran pengendalian mutu statistik yaitu mengevaluasi proses sehingga meminimalkan variasi yang terjadi pada setiap proses.

\subsection{Peta Kendali}

Control chart atau Peta Kendali merupakan salah satu dari alat QC 7 tools (7 alat pengendalian Kualitas) yang berbentuk grafik dan dipergunakan untuk memonitor atau memantau stabilitas dari suatu proses serta mempelajari perubahan proses dari waktu ke waktu. Control Chart memiliki Upper Line (garis atas) untuk Upper Control Limit (Batas Kontrol tertinggi), Lower Line (garis bawah) untuk Lower control limit (Batas kontrol terendah) dan Central Line (garis tengah) untuk rata-rata (Average). Data yang dimasukkan berupa titik-titik yang kemudian digambarkan garis untuk memperlihatkan grafiknya.

Tujuan dari pembuatan peta kendali adalah untuk menentukan hasil kerja suatu proses dalam keadaan normal atau tidak normal. Keragaman yang terjadi disetiap proses yang menyebabkan setiap proses tidak normal adalah suatu hal yang wajar, keragaman muncul dari berbagai jenis penyebab seperti kesalahan petugas, kesalahan alat dan lain sebagainya [2].

\subsubsection{Peta Kendali $U$}

Peta kendali $U$ untuk data dengan ukuran sampel yang tidak sama, nilai dari $\bar{u}$ dapat diperoleh dengan [3],

$$
\bar{u}=\frac{\sum_{i=1}^{m} c_{i}}{\sum_{i=1}^{m} n_{i}}
$$

Untuk banyaknya ketidaksesuaian dalam peta kendali $U$ dihitung dengan [3]

$$
u_{i}=\frac{c_{i}}{n_{i}} \quad i=1,2, \cdots, n .
$$

Batas kendali untuk peta kendali $U$ dapat dihitung dengan:

$$
\begin{aligned}
U C L_{i} & =\bar{u}+3 \sqrt{\frac{\bar{u}}{n_{i}}} \\
C L & =\bar{u}=\frac{\sum_{i=1}^{m} c_{i}}{\sum_{i=1}^{m} n_{i}} \\
L C L_{i} & =\bar{u}-3 \sqrt{\frac{\bar{u}}{n_{i}}}
\end{aligned}
$$

dimana $u_{i}=$ banyak ketidaksesuaian sampel tiap unit ke- $i, c_{i}=$ jumlah produk ketidaksesuaian tiap unit pada observasi ke- $i, n_{i}=$ ukuran sampel yang diambil tiap unit pada observasi ke- $i$ dan $m=$ banyaknya sampel. 


\subsubsection{Peta Kendali Decision On Belief (DOB)}

Peta kendali DOB merupakan peta kendali yang digunakan untuk mengendalikan data pengamatan tunggal yang karakteristiknya atribut. Peta kendali DOB digunakan untuk mengontrol kualitas data univariat. Misalkan $O_{k}=$ $\left(x_{1}, x_{2}, \cdots, x_{k}\right)$ menjadi vektor pengamatan pada iterasi ke- $k$, dimana $x_{i} ; i=$ $1,2, \cdots$ adalah pengamatan jumlah ketidaksesuaian dari produk yang diteliti. Pengukuran ini merupakan peluang dari proses yang akan berada dalam keadaan in control berdasarkan vektor pengamatan yang diperoleh sampai pada iterasi ke $k-1$ dan pengamatan pada iterasi ke $k$. Selanjutnya dimisalkan bahwa $B\left(x_{k-1}, O_{k-2}\right)$ juga dalam keadaan in control, untuk memperbarui anggapan $B\left(x_{k}, O_{k-1}\right)$ diasumsikan bahwa [7]

$$
B\left(x_{k}, O_{k-1}\right)=\frac{B\left(O_{k-1}\right) e^{\frac{x_{k}-\mu_{0}}{\sigma_{0}}}}{B\left(O_{k-1}\right) e^{\frac{x_{k}-\mu_{0}}{\sigma_{0}}}+\left(1-B\left(O_{k-1}\right)\right)}
$$

$\mu$ merupakan rata-rata jumlah cacat, selanjutnya didefinisikan statistik baru $Z_{k}$ sebagai berikut

$$
Z_{k}=\frac{B\left(x_{k}, O_{k-1}\right)}{1-B\left(x_{k}, O_{k-1}\right)}=\frac{B\left(O_{k}\right)}{1-B\left(O_{k}\right)}
$$

Kemudian persamaan (2.1) disubstitusikan ke persamaan (2.2) sehingga menjadi

$$
Z_{k}=\frac{\left(\frac{B\left(O_{k-1}\right) e^{\frac{x_{k}-\mu_{0}}{\sigma_{0}}}}{B\left(O_{k-1}\right) e^{\frac{x_{k}-\mu_{0}}{\sigma_{0}}}+\left(1-B\left(O_{k-1}\right)\right)}\right)}{1-\left(\frac{B\left(O_{k-1}\right) e^{\frac{x_{k}-\mu_{0}}{\sigma_{0}}}}{B\left(O_{k-1}\right) e^{\frac{x_{k}-\mu_{0}}{\sigma_{0}}}+\left(1-B\left(O_{k-1}\right)\right)}\right)}
$$

Dari persamaan (2.2) diketahui bahwa $Z_{k}=\frac{B\left(O_{k}\right)}{1-B\left(O_{k}\right)}$, sehingga untuk $k-1$ diperoleh $Z_{k-1}=\frac{B\left(O_{k-1}\right)}{1-B\left(O_{k-1}\right)}$. Dengan demikian persamaan (2.3) menjadi,

$$
Z_{k}=\exp \left(\frac{x_{k}-\mu_{0}}{\sigma_{0}}\right) Z_{k-1}
$$

Karena $Z_{k}=\exp \left(\frac{x_{k}-\mu_{0}}{\sigma_{0}}\right) Z_{k-1}$, maka persamaan (2.4) dapat dijabarkan sebagai berikut,

$$
\begin{aligned}
& Z_{k}=e^{\frac{x_{k}-\mu_{0}}{\sigma_{0}}}\left[e^{\frac{x_{k-1}-\mu_{0}}{\sigma_{0}}} Z_{k-2}\right]=e^{\frac{x_{k}-\mu_{0}}{\sigma_{0}}+\frac{x_{k-1}-\mu_{0}}{\sigma_{0}}+\cdots+\frac{x_{1}-\mu_{0}}{\sigma_{0}}} Z_{0} \\
& Z_{k}=e^{\frac{\left(\sum_{i=1}^{k} x_{i}\right)-k \mu_{0}}{\sigma_{0}}} Z_{0}
\end{aligned}
$$

Jika diberikan $k=1$ pada persamaan (2.5) maka diperoleh [7],

$$
Z_{1}=\exp \left(\frac{\sum_{i=1}^{1} x_{1}-1 \mu_{0}}{\sigma_{0}}\right) Z_{0}=\exp \left(\frac{x_{1}-\mu_{0}}{\sigma_{0}}\right) Z_{0}
$$


Pada persamaan (2.2) tetapkan $k=0$ sehingga diperoleh

$$
Z_{0}=\frac{B\left(O_{0}\right)}{1-B\left(O_{0}\right)}
$$

Kemudian tetapkan $Z_{0}=1$, sehingga [7]

$$
\begin{aligned}
1 & =\frac{B\left(O_{0}\right)}{1-B\left(O_{0}\right)} \\
B\left(O_{0}\right) & =0,5
\end{aligned}
$$

Nilai $B\left(O_{0}\right)=0,5$ diperoleh sebagai nilai awal untuk peta kendali DOB [7].

Untuk menghilangkan eksponensial, persamaan (2.5) dapat disederhanakan menjadi

$$
\ln Z_{k}=\frac{\sum_{i=1}^{k} x_{i}-k \mu_{0}}{\sigma_{0}}+\ln Z_{0}
$$

Karena sudah ditetapkan $Z_{0}=1$ maka $\ln Z_{k}=\frac{\sum_{i=1}^{k} x_{i}-k \mu_{0}}{\sigma_{0}}$ [7].

Bentuk persamaan (2.8) mengikuti bentuk distribusi normal baku. Dengan demikian $\ln \left(Z_{k}\right) \sim N(0, k)$ atau $\frac{\ln Z_{k}}{\sqrt{k}} \sim N(0,1)$ sehingga interval kepecayaan $(1-\alpha) 100 \%$ untuk $\frac{\ln Z_{k}}{\sqrt{k}}$ adalah $[7]$

$$
\begin{array}{r}
P\left(-c<\frac{\ln Z_{k}}{\sqrt{k}}<c\right)=1-\alpha \\
P\left(-c \sqrt{k}<\ln Z_{k}<c \sqrt{k}\right)=1-\alpha
\end{array}
$$

Kemudian didefinisikan UCL dan LCL model peta kendali Shewhart's untuk $\ln \left(Z_{k}\right)$ sebagai berikut $[7]$

$$
U C L_{\ln \left(Z_{k}\right)}=\mu+c \sigma=c \sqrt{k} \operatorname{dan} U C L_{\ln \left(Z_{k}\right)}=\mu-c \sigma=-c \sqrt{k}
$$

dimana $c$ adalah kelipatan simpangan baku dari $\ln \left(Z_{k}\right)$ dan nilainya ditetapkan. Untuk peubah acak yang berdistribusi normal, ditetapkan nilai $c=1,5$. [7]

Selanjutnya substitusikan persamaan (2.2) ke persamaan (2.9) sehingga diperoleh

$$
P\left(-c \sqrt{k} \leq \ln \left(\frac{B\left(x_{k}, O_{k-1}\right)}{1-B\left(x_{k}, O_{k-1}\right)}\right) \leq c \sqrt{k}\right)=1-\alpha
$$

dan

$$
P\left(\frac{e^{-c \sqrt{k}}}{e^{-c \sqrt{k}}+1} \leq B\left(x_{k}, O_{k-1}\right) \leq \frac{e^{c \sqrt{k}}}{e^{c \sqrt{k}}+1}\right)=1-\alpha
$$

Jadi interval kepercayaan $(1-\alpha) 100 \%$ untuk $B\left(x_{k}, O_{k-1}\right)$ adalah sebagai berikut

$$
P\left(\frac{e^{-c \sqrt{k}}}{e^{-c \sqrt{k}}+1} \leq B\left(x_{k}, O_{k-1}\right) \leq \frac{e^{c \sqrt{k}}}{e^{c} \sqrt{k}+1}\right)=1-\alpha
$$


sehingga didapatkan UCL dan LCL untuk $B\left(x_{k}, O_{k-1}\right)$, sebagai berikut [7]

$$
\begin{gathered}
U C L_{B\left(x_{k}, O_{k-1}\right)}=\frac{e^{c \sqrt{k}}}{e^{c \sqrt{k}}+1} \\
L C L_{B\left(x_{k}, O_{k-1}\right)}=\frac{e^{-c \sqrt{k}}}{e^{-c \sqrt{k}}+1}
\end{gathered}
$$

Dengan demikian diperoleh batas-batas kendali untuk peta kendali DOB adalah berdasarkan persamaan (2.13) dan (2.14) yang digunakan untuk melihat data terkendali atau tidaknya secara statistik.

\section{Pembahasan}

\subsection{Uji Normalitas Data}

Pengujian distribusi normal yang digunakan adalah uji Kolmogorov-Smirnov. Uji normalitas Kolmogorov-Smirnov dapat diperoleh menggunakan software Minitab. Hal ini dapat dilihat pada Gambar 3.1.

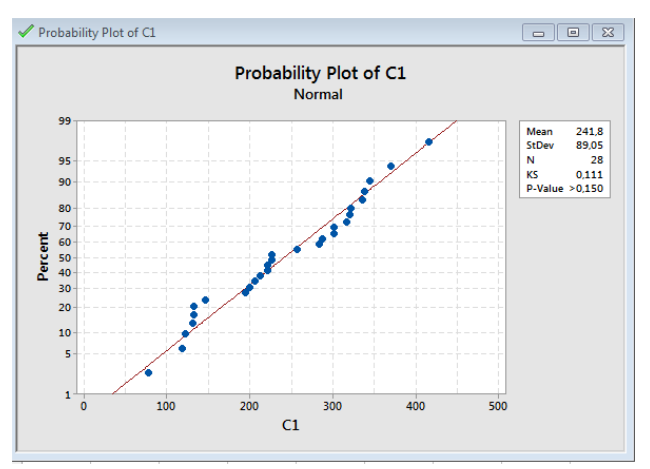

Gambar 3.1: Uji Normalitas Data Reject Produksi Lampu TL

Berdasarkan Gambar 3.1 diatas terlihat bahwa $P$-value $>\alpha=0,05$ sehingga $H_{0}$ diterima dan data berdistribusi normal.

\subsection{Peta Kendali $U$}

Pada bagian ini akan dijelaskan tentang pengendalian kualitas produk reject dari produksi pembuatan lampu TL menggunakan peta kendali $U$ karena data sampel yang digunakan adalah berbeda-beda, sehingga diperoleh grafik sebagai berikut.

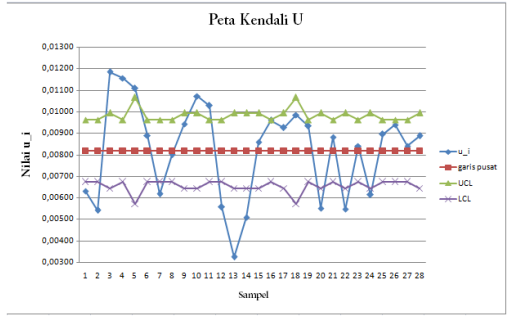

Gambar 3.2 Peta Kendali U 
Dari output yang telah diperoleh diatas dapat dilihat bahwa terdapat 14 buah titik yang berada diluar peta kedali (out of control). Dapat disimpulkan dari Gambar 3.2 bahwa produksi pembuatan lampu TL belum terkendali secara statistik.

\subsection{Peta Kendali Decision On Belief(DOB)}

Pengendalian kualitas produk reject pembuatan lampu TL di VTL (unit) 1 subproses stem making \& mounting PT Philips Indonesia dilakukan dengan menggunakan peta kendali DOB. Dari data statistik diperoleh grafik peta kendali DOB sebagai berikut :

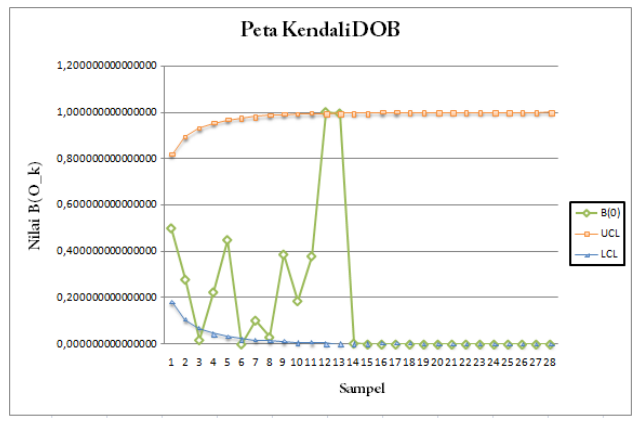

Gambar 3.3 Peta Kendali DOB

Dari output diatas dapat dilihat bahwa terdapat 19 buah titik yang berada diluar peta kendali atau (out of control). Dapat dilihat dari Gambar 3.3 bahwa produksi reject pembuatan lampu TL belum terkendali secara statistik.

\subsection{Perbandingan Output Peta Kendali U dan Peta Kendali DOB}

Perbandingan jumlah data out of control dari kedua peta kendali dapat dilihat pada tabel berikut

Tabel 3.1: Perbandingan Persentase Jumlah DataOut Of Control

\begin{tabular}{|c|c|c|}
\hline Peta Kendali & Jumlah Data Out Of Control & Persentase \\
\hline U & 14 & $50 \%$ \\
\hline DOB & 19 & $67,86 \%$ \\
\hline
\end{tabular}

Berdasarkan Tabel 3.1, dapat dilihat bahwa pengendalian kualitas produk reject pembuatan lampu TL di VTL (unit) 1 subproses stem making \& mounting PT Philips Indonesia bahwa peta kendali DOB mendeteksi data out of control yang lebih banyak daripada peta kendali $U$. Dengan demikian dapat dikatakan bahwa performa atau kinerja peta kendali DOB lebih baik daripada peta kendali $U$.

\section{Kesimpulan}

Berdasarkan hasil penelitian diperoleh kesimpulan bahwa pengendalian kualitas dengan peta kendali $U$ dan peta kendali DOB belum terkendali secara statistik. 
Peta kendali DOB menunjukkan kinerja yang lebih baik daripada peta kendali $U$, karena mampu mendeteksi jumlah data out of control lebih banyak sebesar $17,86 \%$ dibandingkan dengan menggunakan peta kendali $U$.

\section{Ucapan Terima kasih}

Penulis mengucapkan terimakasih kepada semua pihak yang telah memberikan masukan dan saran sehingga paper ini dapat diselesaikan dengan baik.

\section{Daftar Pustaka}

[1] Grant, E.L dan Leavenworth, R.S. Alih Bahasa oleh Kandahjaya, Hudaya. 1996. Pengendalian Mutu Statistik. Jakarta: Penerbit Erlangga.

[2] Montgomery, D. C. 2019. Statistical Quality Control, Six Edition. John Wiley \& Sons: United States of America.

[3] V. Neubauer, Dean. 2010. Manual on Presentation of Data and Control .Chart Analysis 8th Edition. U.S.A : International Standards Worldwide.

[4] Nezhad, M. S. F. dan Niaki, S.T.A. 2010. A New Monitoring Design for Univariate Statistical Quality Control Charts. Information Science, 180, 1051 1059.

[5] Nurhayati. 2015. Analisis Pengendalian Kualitas Pada Proses Lampu TL Di PT Philips Indonesia. Tugas Akhir. Surabaya : Institut Teknologi Sepuluh Nopember.

[6] Walpole, E.R. 1998. Pengantar Statistika Edisi Ketiga. PT Gramedia Pustaka Utama: Jakarta.

[7] Widjajati, F. A., Nuri W. dan Lisda S. H. (2016). Quality Control Analysis of The Water Meter Tools Using Decision On Belief (DOB) Control Chart in PDAM Surya Sembada Surabaya. International Journal of Computing Science and Applied Mathematics, Vol. 2, no. 1. 